\title{
Sodium alterations impair the prognosis of hospitalized patients with COVID-19 pneumonia
}

\author{
Marianna Martino D, Paolo Falcioni, Giulia Giancola, Alessandro Ciarloni, Gianmaria Salvio, Francesca Silvetti, \\ Augusto Taccaliti and Giorgio Arnaldi
}

Division of Endocrinology and Metabolic Diseases, Department of Clinical and Molecular Sciences (DISCLIMO), Polytechnic University of Marche, Ancona, Italy

Correspondence should be addressed to G Arnaldi: g.arnaldi@staff.univpm.it

\begin{abstract}
Objective: Dysnatremia is common in hospitalized patients, often worsening the prognosis in pneumopathies and critical illnesses. Information on coronavirus disease-19

(COVID-19)-related hyponatremia is partially conflicting, whereas data on hypernatremia in this context are scarce. We assessed, in a cohort of COVID-19 inpatients: the prevalence of sodium alterations at admission and throughout their hospitalization; their association with inflammation/organ damage indexes; their short-term prognostic impact.

Study design and methods: 117 patients (81 males, $64 \pm 13$ years) hospitalized for

COVID-19 between 1 March and 30 April 2020 were retrospectively followed-up for their first 21 days of stay by collecting all serum sodium measurements, basal CRP and serum lactate levels, maximum IL- 6 and information on care setting, required ventilation, length of hospitalization, in-hospital death.

Results: At admission, 26.5\% patients had hyponatremia, and 6.8\% had hypernatremia. During their hospitalization, $13.7 \%$ patients experienced both disorders ('mixed dysnatremia'). Lower sodium levels at admission were correlated with higher $C$ reactive protein (CRP) $(P=0.039)$ and serum lactate levels $(P=0.019)$, but not interleukin-6 (IL-6). Hypernatremia and a wider sodium variability were associated with maximum required ventilation, need for ICU assistance and duration of the hospitalization. Mean estimated time to Intensive Care Unit (ICU) admission was 20 days shorter in patients exposed to sodium alterations at any time of their hospital course (log-rank test $P=0.032$ ).

Conclusions: Sodium alterations frequently affect hospitalized COVID-19 patients.

Hyponatremia could indicate pulmonary involvement, whereas hypernatremia is associated to prolonged hospitalization and the need for intensive care/mechanical ventilation, particularly when resulting from prior hyponatremia. Optimizing in-hospital sodium balance is crucial to improve patients' prognosis.
\end{abstract}

Key Words

- SARS-CoV-2

\section{Introduction}

Hyponatremia (serum sodium concentration < $135 \mathrm{mmol} / \mathrm{L}$ ) is the most common disorder of water balance in hospitalized patients, with a reported prevalence of $30 \%$ and a negative prognostic impact in the elderly, as well as in patients with heart failure, liver cirrhosis, cancer and pulmonary diseases $(1,2)$.
Hyponatremia complicates up to $30 \%$ pneumonias and its association with a higher risk of mechanical ventilation in intensive care units (ICU), longer hospitalizations, recurrence and death is well established $(3,4,5,6,7,8,9,10)$.

In the majority of cases, para-pneumonic hyponatremia is sustained by a syndrome of inappropriate

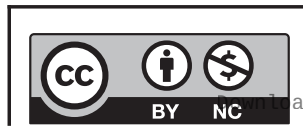

This work is licensed under a Creative Commons Attribution-NonCommercial 4.0 International License. ded from Bioscientifica.com at 04/26/2023 09:04:25AM 
anti-diuresis (SIAD), where hypoxia and inflammatory cytokines, such as monocyte and macrophage-derived interleukin 6 (IL-6), induce a non-osmotic vasopressin release $(11,12)$. In predisposed individuals infected by the novel coronavirus SARS-CoV-2, IL-6 is also the main actor implied in the 'cytokine storm', which causes the evolution of coronavirus disease-19 (COVID-19) pneumonia toward aggressive, life-threatening acute respiratory distress syndrome (ARDS) requiring intensive care management $(13,14,15,16,17)$. In turn, intensive care management of critically ill patients is frequently associated with hypernatremia (serum sodium concentration $>145 \mathrm{mmol} / \mathrm{L}$ ), with a $6 \%$ prevalence at ICU admission and a 4-26\% incidence throughout ICU stay $(18,19)$. Hypernatremia is mainly iatrogenic, due to a positive sodium balance induced by free water loss. Recently, also this disorder has been associated with longer hospitalizations, readmissions after discharge and higher mortality rates, regardless of its underlying medical condition and degree $(20,21,22,23)$.

The first, retrospective Chinese data on hyponatremia in COVID-19 pneumonia reported a $10-27 \%$ prevalence, which is far lower than the $60 \%$ previously demonstrated for SARS-CoV-1 $(24,25,26)$. Data from a recent metaanalysis on the same topic showed a pooled incidence of $16-31 \%$ for hyponatremia (27), which has been directly correlated with $\mathrm{PaO}_{2} / \mathrm{FiO}_{2}$ ratio, inversely with IL-6 and associated with worse COVID-19 outcomes (non-invasive ventilation, ICU transfer, death) $(24,28,29,30,31,32,33$, $34,35)$. Despite its prognostic value in critical illnesses, data concerning COVID-19-related hypernatremia are scarce $(24,33,34,35)$; specifically, only one study looked for the development of hypernatremia in COVID-19 inpatients, showing this was associated with in-hospital mortality (35).

We, therefore, aimed to investigate, in a retrospective cohort of inpatients with COVID-19 pneumonia, the prevalence of sodium alterations at hospital admission and their association with: (a) sodium balance throughout and at the end of the hospitalization; (b) biochemical inflammation and organ damage indexes: $C$ reactive protein (CRP), IL-6, serum lactate levels (Lac); (c) outcome measures: maximum required ventilation, need for ICU assistance, duration of the hospitalization and in-hospital death.

\section{Materials and methods}

\section{Study design}

This was an open-label, observational study conducted at Ancona University Hospital (Ancona, Italy) on a cohort of patients hospitalized for COVID-19 pneumonia between 1 March and 30 April 2020 and consecutively enrolled. The study was conducted according to the Declaration of Helsinki and approved by the local Ethic Committee.

\section{Patients and methods}

The study cohort included 117 patients (81 males and 36 females), aged $64 \pm 13$ (25-90) years.

Data were retrospectively collected from the local Laboratory Analysis database, following up patients' serum sodium levels during their first 21 days of hospitalization, which is the median timeframe between onset of COVID-19 symptoms and hospital discharge (29). Information on patients' care setting (sub-intensive vs ICU), maximum required ventilation (ambient air vs noninvasive ventilation delivery vs mechanical ventilation), duration of hospitalization, outcome (discharged vs dead) was obtained from available clinical documentation.

The term 'non-invasive ventilation delivery' included oxygen therapy delivered through nasal cannulae, ventimask, continuous positive airway pressure (C-PAP), and Bi-Phasic PAP (BiPAP), while the term 'mechanical ventilation' included oro-tracheal intubation and tracheostomy.

Serum sodium levels were measured according to patients' clinical needs, and all available values were recorded for each patient (average 11 values/ patient). Data were analyzed first in the whole cohort, by stratifying patients in quartiles according to serum sodium at admission (Q1 $\leq 134$, Q2 135-139, Q3 140-141, Q4 $\geq 142 \mathrm{mmol} / \mathrm{L}$ ), then patients were divided into the following three groups according to their first serum sodium level: (group A) hyponatremic $(<135 \mathrm{mmol} / \mathrm{L})$, (group B) normonatremic (135-145 mmol/L), (group C) hypernatremic $(>145 \mathrm{mmol} / \mathrm{L})$. Comparisons were made among the three groups. Moreover, sodium alterations were stratified in mild, moderate, and severe as follows: for hyponatremia, serum sodium 130-134, 125-129 and <125 $\mathrm{mmol} / \mathrm{L}$, respectively; for hypernatremia, serum sodium 146-150, 151-155 and $>155 \mathrm{mmol} / \mathrm{L}$, respectively. CRP and Lac levels were available for all patients at admission, whereas IL-6 had been measured more sparsely: for this reason, we chose to consider CRP levels (normal range 0.0$0.6 \mathrm{mg} / \mathrm{dL}$ ) at admission and maximum IL-6 levels (normal range $0.00-5.20 \mathrm{pg} / \mathrm{mL}$ ) as inflammation indexes, while Lac levels at admission estimated by blood gas analysis (normal range $0.00-2.40 \mathrm{mmol} / \mathrm{L}$ ) were used as tissue oxygenation/ organ damage index.

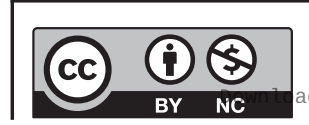

This work is licensed under a Creative Commons Attribution-NonCommercial 4.0 International License. ed from Bioscientifica.com at 04/26/2023 09:04:25AM 


\section{Statistical analysis}

Variables are presented as mean \pm S.D. (range) if continuous, number and percentage if categorical, mean and corresponding 95\% CI if ordinal. After verifying the normal distribution of quantitative variables with the Kolmogorov-Smirnov test, comparisons between two groups were made with the Student's $t$-test (normal distribution) or the Mann-Whitney test (non-normal distribution). For comparisons concerning more than two groups, the ANOVA (parametric) or the Kruskal-Wallis (non-parametric) tests were applied. The Bonferroni test was used for post hoc analyses. Categorical variables were compared with the chi-square $\left(\chi^{2}\right)$ or the Fisher's exact test, where appropriate. The Pearson's P and the Spearman's Rho ( $\rho$ ) were used for the bi-varied correlation analyses, as appropriate. The odds ratio (OR) was used to verify outcomes. The Kaplan-Meier method was used to calculate survival distributions. A $P$ value of 0.050 was considered for the statistical significance. The SPSS software version 20.0 (IBM SPSS Statistics for Windows; Armonk, NY, USA) was used for statistical analysis.

\section{Results}

\section{Whole cohort}

Table 1 illustrates demography, outcome measures and biochemical indexes.

Mean serum sodium at admission $\left(\mathrm{Na}^{+}{ }_{\text {in }}\right)$ was $138 \pm 6$ (121-150) $\mathrm{mmol} / \mathrm{L}$. The sodium nadir $\left(\mathrm{Na}^{+}{ }_{\text {min }}\right)$ was in mean
$134 \pm 6$ (117-144) $\mathrm{mmol} / \mathrm{L}$. $\mathrm{Na}^{+}{ }_{\text {min }}$ was reached within the second day of hospitalization in $62.4 \%$ patients (day 1 for 59 patients, day 2 for 14 patients) and was strongly correlated with $\mathrm{Na}^{+}$in $(P=0.761, P<0.001)$. A significant $(P<0.001)$, progressive increase in mean serum sodium levels was subsequently observed until a maximum $\left(\mathrm{Na}^{+}{ }_{\text {max }}\right)$ of $147 \pm 5(138-163) \mathrm{mmol} / \mathrm{L}$. Sodium fluctuation between the extremes $\left(\Delta \mathrm{Na}^{+}{ }_{\text {min-max }}\right)$ was $12 \pm 6(1-28)$ $\mathrm{mmol} / \mathrm{L}$, occurring in a 5-day interval in mean. The last available sodium measurement $\left(\mathrm{Na}^{+}{ }_{\text {out }}\right)$ was in mean $142 \pm 5$ (131-162) mmol/L. Mean sodium variation from admission to the last assessment $\left(\Delta \mathrm{Na}^{+}{ }_{\text {in-out }}\right)$ was $5 \pm 7$ $(-10$ to +22$) \mathrm{mmol} / \mathrm{L}$.

At hospital admission, $78(66.7 \%)$ patients had normal sodium levels, 31 (26.5\%) were hyponatremic and $8(6.8 \%)$ had hypernatremia. Of the 117 patients, 39 (33.3\%) maintained normal sodium levels throughout the hospitalization; sodium levels varied between hypo- and normonatremia in 29 (24.8\%) patients and between normo- and hypernatremia in 33 (28.2\%) patients. A wider fluctuation including both hypo- and hypernatremia ('mixed dysnatremia') was observed in the remaining $16(13.7 \%)$ patients. The last available sodium check showed 93 (79.5\%) normonatremic, 7 (6.0\%) hyponatremic and 17 (14.5\%) hypernatremic patients. Information on serum sodium levels and distribution of sodium alterations according to gender, admission care setting, need for ICU, maximum requested ventilation and patients' outcome is available in Supplementary Tables 1 and 2 (see section on supplementary materials given at the end of this article).

Table 1 Demographic data, outcome measures and biochemical indexes. Data are expressed as mean \pm S.D. (minimummaximum range) or as number and percentage.

\begin{tabular}{|c|c|c|c|c|c|}
\hline & $\begin{array}{l}\text { Whole cohort } \\
\qquad(n=117)\end{array}$ & $\begin{array}{l}\text { Hyponatremic } \\
\text { (group A, } n=31 \text { ) }\end{array}$ & $\begin{array}{c}\text { Normonatremic } \\
\text { (group B, } n=78 \text { ) }\end{array}$ & $\begin{array}{l}\text { Hypernatremic } \\
\text { (group } C, n=8 \text { ) }\end{array}$ & $P$ value \\
\hline Age (years) & $64 \pm 13(25-90)$ & $61 \pm 12(25-83)$ & $63 \pm 13(36-90)$ & $71 \pm 11(53-88)$ & 0.190 \\
\hline Gender (Male) & $81(69)$ & $23(28)$ & $51(63)$ & $7(9)$ & 0.341 \\
\hline ICU admission & $18(15)$ & 7 (39) & $10(56)$ & $1(5)$ & 0.432 \\
\hline $\begin{array}{l}\text { Need for mechanical } \\
\text { ventilation in ICU }\end{array}$ & $32(27)$ & $10(31)$ & $21(66)$ & $1(3)$ & 0.530 \\
\hline $\begin{array}{l}\text { Length of hospital } \\
\text { stay (days) }\end{array}$ & $33 \pm 22(4-120)$ & $29 \pm 17(7-82)$ & $27 \pm 22(4-120)$ & $27 \pm 18(11-66)$ & 0.391 \\
\hline Death & $20(17)$ & $4(20)$ & $15(75)$ & $1(5)$ & 0.686 \\
\hline $\begin{array}{l}\text { IL-6, maximum } \\
(\mathrm{pg} / \mathrm{mL})\end{array}$ & $\begin{array}{c}404.9 \pm 776.7 \\
(7.4-4601.0)\end{array}$ & $\begin{array}{c}325.1 \pm 450.6 \\
(9.8-2140.0)\end{array}$ & $\begin{array}{c}342.7 \pm 623.5 \\
(3.5-3207.0)\end{array}$ & $\begin{array}{c}1001.2 \pm 1784.8 \\
(61.1-4601.0)\end{array}$ & 0.385 \\
\hline $\begin{array}{l}\text { CRP, admission } \\
\text { (mg/dL) }\end{array}$ & $8.6 \pm 8.0(0.6-41.5)$ & $10.5 \pm 10.0(1.0-41.5)$ & $7.0 \pm 5.7(0.3-27.3)$ & $3.5 \pm 2.4(0.3-6.2)$ & 0.029 (A vs C) \\
\hline $\begin{array}{l}\text { Lac, admission } \\
(\mathrm{mmol} / \mathrm{mol})\end{array}$ & $0.9 \pm 0.8(0.0-3.6)$ & $1.0 \pm 0.7(0.0-2.5)$ & $0.7 \pm 0.8(0.0-3.6)$ & $0.8 \pm 0.8(0.0-2.0)$ & 0.107 \\
\hline
\end{tabular}

CRP, C reactive protein; ICU, intensive care unit; IL-6, interleukin 6; Lac, serum lactate levels. Bold indicates statistical significance, $P=0.029$.

https://ec.bioscientifica.com https://doi.org/10.1530/EC-21-0411 (c) 2021 The authors Published by Bioscientifica Ltd

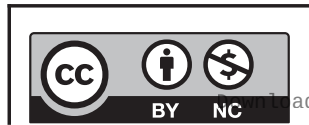

This work is licensed under a Creative Commons Attribution-NonCommercial 4.0 International License. ded from Bioscientifica.com at 04/26/2023 09:04:25AM via free access 
Maximum required ventilation, need for ICU transfer and death were similar among $\mathrm{Na}^{+}{ }_{\text {in }}$ quartiles.

There was a significant difference among quartiles in basal CRP $(P=0.039)$, which was inversely correlated with $\mathrm{Na}^{+}{ }_{\text {in }}(\rho=-0.275, P=0.006)$. Although similar among quartiles, Lac was inversely correlated with $\mathrm{Na}^{+}{ }_{\text {in }}(\rho=-0.216$, $P=0.019)$ and $\mathrm{Na}^{+}{ }_{\text {min }}(\rho=-0.241, P=0.009)$. Multivariate analyses showed that neither $\mathrm{Na}^{+}{ }_{\text {in }}$ nor $\mathrm{Na}^{+}{ }_{\text {min }}$ influenced the risk of a IL-6-mediated cytokine storm $(P>0.050)$.

A higher $\mathrm{Na}^{+}{ }_{\text {max }}$ was correlated not only with a longer hospitalization $(\rho=0.344, P<0.001)$ but also with the need for higher intensity of care $(\rho=0.338, P<0.001$ for ICU admission, $\rho=0.415, P<0.001$ for ICU need) and more invasive ventilation $(\rho=0.394, P<0.001)$. Moreover, ICU admission, need for ICU assistance and a more invasive ventilation correlated with $\Delta \mathrm{Na}^{+}{ }_{\text {min-max }}$ ( $\rho=0.695, P<0.001 ; \rho=0.318, P<0.001$ and $\rho=0.269$, $P=0.006$, respectively) and hypernatremia/mixed dysnatremia $(\rho=0.380,0.420$ and 0.410 respectively, $P<0.001)$. In this regard, the estimated time to ICU admission for patients experiencing sodium alterations was 20 days shorter than that of normonatremic patients, as shown by the Kaplan-Meier curve in Fig. 1 (log-rank test $P=0.032$ ).

The 21-day serum sodium trend of patients requiring ICU assistance in any moment of their hospitalization was specular to that of patients never requiring ICU admission. Sodium levels did not influence the risk of in-hospital death $(P>0.050)$, which was correlated only with patients' age $(\rho=0.260, P=0.005)$ : patients who died during the hospitalization were significantly older than those who were discharged ( $71 \pm 11$ vs $62 \pm 12$ years, $P=0.003$ ), the latter having a longer hospitalization $(29 \pm 20$ vs $18 \pm 17$ days, $P=0.001$ ).

Considering only in-hospital survivors, duration of the hospitalization was not only associated with ICU admission ( $\rho=0.303, P=0.003)$ or ICU need at any time $(P=0.489$, $P<0.001)$ but also with sodium levels: particularly, a longer hospitalization was correlated with a lower $\mathrm{Na}^{+}{ }_{\text {min }}$ $(\rho=-0.210, P=0.039)$, a higher $\mathrm{Na}^{+}{ }_{\text {max }}(P=0.510, P<0.001)$ and a wider $\Delta \mathrm{Na}^{+}{ }_{\text {min-max }}(P=0.453, P<0.001)$.

\section{Hypo- (group A) vs normo- (group B) vs hypernatremic (group C) patients}

Demography, outcome measures and biochemical indexes related to the three groups of patients are described in Table 1.

Figure 2 illustrates serum sodium trend throughout the 21-day observation in the three groups of patients:

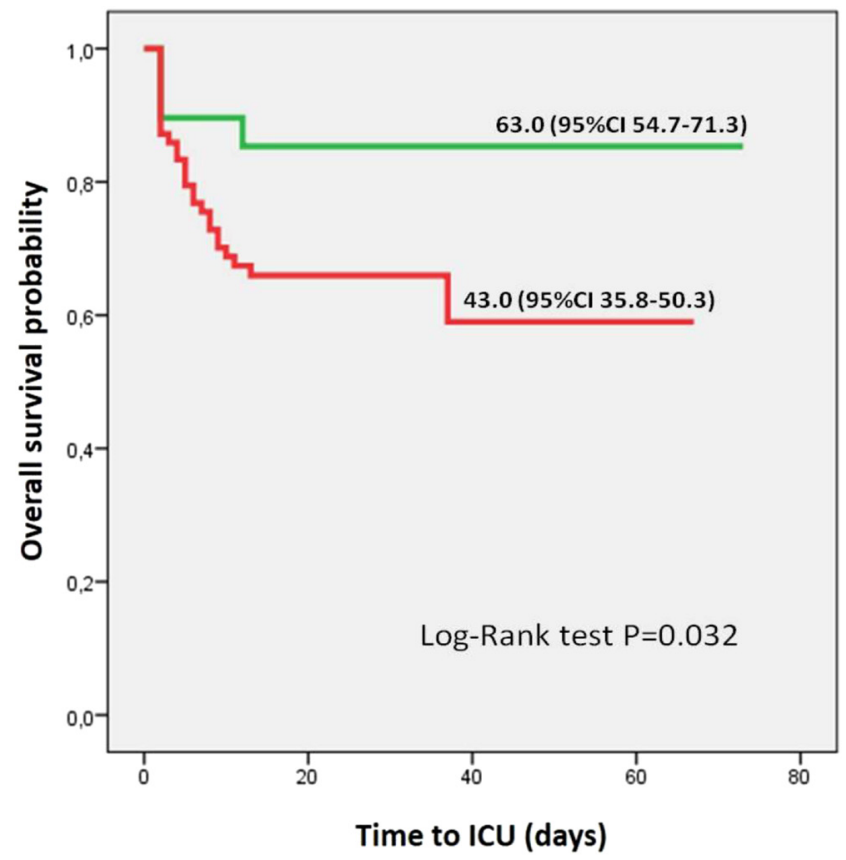

Natremia, trend during hospital stay

$\neg$ at least one alteration $(n=78)$

$\neg$ always normal $(n=39)$

\section{Figure 1}

Estimated probability of ICU request according to patients' sodium trend throughout their hospital stay.

while both group A and group B curves were close to the trend exhibited by the whole cohort, group C curve had a peculiar, saw-tooth pattern. Moreover, the distribution of sodium pattern throughout the hospitalization was significantly different among groups: of note, $65 \%$ patients from group A persisted hyponatremic or normalized their serum sodium, but 35\% experienced mixed dysnatremia $(P<0.001)$; while half patients from group B preserved their sodium balance, $12 \%$ developed hyponatremia, 33\% evolved toward hypernatremia and $5 \%$ experienced mixed dysnatremia $(P<0.001)$; mixed dysnatremia was encountered only in one $(12 \%)$ patient from group C, where the majority (88\%) of patients persisted hypernatremic or normalized their serum sodium $(P<0.001)$. However, the distribution of sodium alterations at the end of the observation was similar among the three groups $(P=0.286)$, with normal $\mathrm{Na}^{+}{ }_{\text {out }}$ levels in 80,81 and $63 \%$ patients from groups $\mathrm{A}, \mathrm{B}$ and $\mathrm{C}$ respectively. Low $\mathrm{Na}^{+}$out levels were found in 10 and 5\% patients from groups $\mathrm{A}$ and $\mathrm{B}$, respectively, with no group $\mathrm{C}$ involvement. Elevated $\mathrm{Na}^{+}{ }_{\text {out }}$ levels were detected in $10 \%$ group A, $14 \%$ group B and $37 \%$ group C patients.

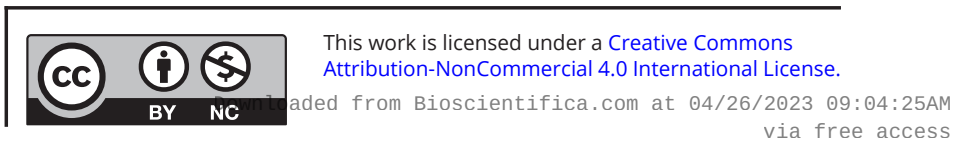




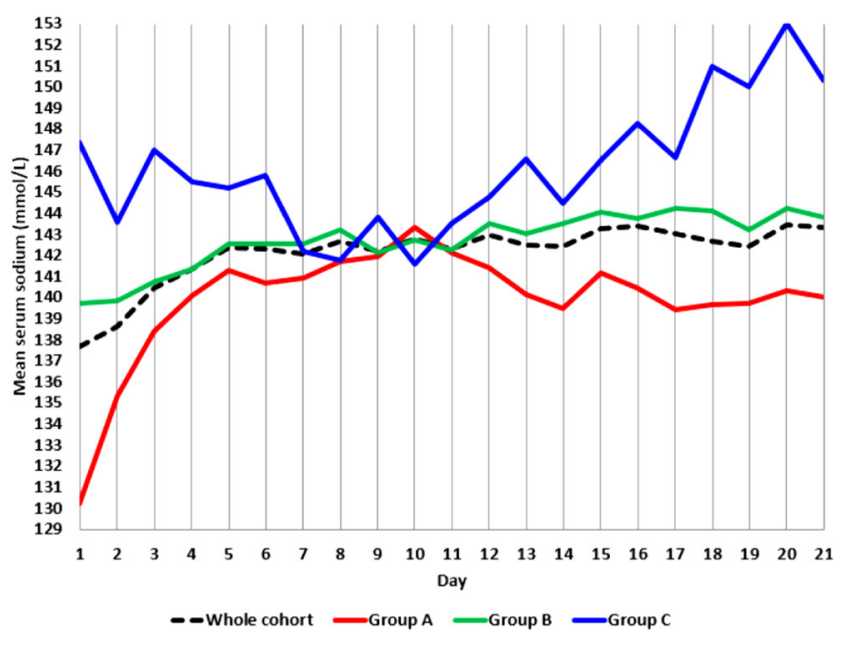

Figure 2

Mean serum sodium levels throughout the 21-day observation: patients divided according to $\mathrm{Na}^{+}$in in hyponatremic (group A), normonatremic (group B) and hypernatremic (group C).

Group A - after stratifying patients according to the degree of hyponatremia ( $64 \%$ mild, $26 \%$ moderate, $10 \%$ severe), no significant differences were found for demographic data, biochemical inflammation and organ damage indexes, as well as for any outcome measures.

Group $B-\Delta \mathrm{Na}^{+}{ }_{\text {min-max }}$ was strongly correlated with age $(P=0.815, P=0.014)$ and moderately with the need for ICU assistance and a more invasive ventilation $(\rho=0.369$, $P=0.001$ and $\rho=0.349 P=0.004$, respectively). These two outcomes were also correlated with $\mathrm{Na}^{+}{ }_{\text {max }}(\rho=0.427$ and 0.412 , respectively, $P<0.001)$. A more invasive ventilation and a longer hospitalization were correlated with hypernatremia/mixed dysnatremia $(\rho=0.390, P=0.001$ and $\rho=0.244, P=0.031$, respectively).

Group C - All eight patients had a mild hypernatremia. The elder had higher $\mathrm{Na}^{+}{ }_{\text {max }}(\rho=0.771, P=0.025)$; a higher $\Delta \mathrm{Na}^{+}{ }_{\text {min-max }}$ was strongly correlated with the need for a more invasive ventilation during the hospitalization $(\rho=0.809, P=0.028)$.

\section{Discussion}

In this study, we systematically assessed the epidemiology and prognostic implications of sodium balance disorders in COVID-19 pneumonia by following up 117 patients during their first 21 days of hospitalization.

At admission, 26.5\% patients had hyponatremia: this finding is consistent with data from a meta-analysis on 11,493 COVID-19 patients showing a $24 \%$ pooled incidence for this disorder (27).
If Wu et al. dealt with COVID-19-related hyponatremia from a merely epidemiological point of view (25), several findings in our cohort add crucial information on this topic, since they suggest hyponatremia is a reliable biomarker of active pulmonary involvement in COVID-19: first, sodium nadir occurred very early, within $48 \mathrm{~h}$ from admission in $62.4 \%$ patients; second, the proportion of hyponatremic patients among those directly admitted in ICU to be mechanically ventilated was superior than that of the whole cohort ( $39 \%$ vs $15 \%$, Table 1); third, sodium levels at admission were inversely correlated with biochemical indexes of systemic inflammation and organ damage, such as basal CRP and Lac. Our data concerning the association between hyponatremia and both pneumonia severity and CRP levels are in line with those found by $\mathrm{Hu}$ et al. in a multicentric cohort of 1254 COVID-19 patients from Hubei, even if the observed prevalence of hyponatremia was far lower (9.9\%) in the latter (24).

Unfortunately, we did not find any relationship between $\mathrm{Na}^{+}{ }_{\text {in }}$ and IL- 6 levels. This seems in contrast with the results obtained from larger cohorts $(n=380$ (33), $n=4452$ (32)), where lower sodium levels at hospital admission were inversely correlated with basal IL-6 $(32,33)$. However, our choice to evaluate the maximum, rather than basal, IL-6 levels in order to highlight better the development of a cytokine storm could account for this discrepancy and deserve further exploration. It must be noticed that data from a recent meta-analysis on the laboratory features of 3396 Asian patients with COVID-19 at different degrees of severity provided evidence in favor of lower sodium and higher CRP and lactate dehydrogenase levels in patients with more severe pneumonia, but did not find any significant differences in IL-6 levels between severe and non-severe COVID-19 pneumonia (34).

If the relationship between hyponatremia and COVID-19 pneumonia is a matter of fact $(24,28,29,30$, $31,32,33,34,35,36)$, the link between hyponatremia and in-hospital death was not demonstrated consistently (36).

Here, none of the considered outcome measures (maximum required ventilation, need for ICU assistance, duration of the hospitalization, and in-hospital death) was associated with hyponatremia. However, collecting sodium levels almost daily allowed us to bring an innovative contribution by pointing out the burden of hypernatremia, whose prevalence was non-negligible at admission (6.8\%) and became more important throughout the hospitalization until the end of the observation (14.5\%). The analysis of day-by-day sodium trend revealed not only $28.2 \%$ patients experiencing hypernatremia but

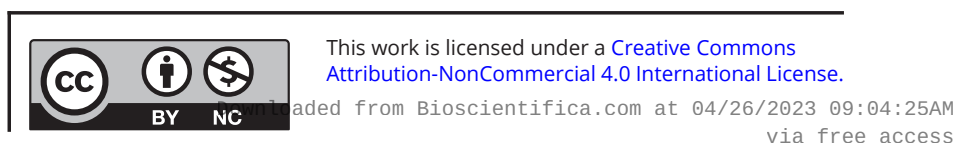


also $13.7 \%$ patients encountering mixed dysnatremia. These data are in line with results from Tzoulis et al., who followed up for 18 days a multicentric cohort of 488 COVID-19 patients, finding a 5.3\% prevalence for hypernatremia at admission, an ascending sodium trend throughout the hospitalization, as well as a $14.3 \%$ prevalence of mixed dysnatremia (36).

At the end of the 21-day observation, the prevalence of hyponatremia decreased to 6\%: serum sodium ascending trend throughout patients' hospitalization reflected their recovery from pneumonia, further supporting the potential of hyponatremia as a biomarker of COVID-19 pulmonary involvement. Moreover, the switch from hypoto hypernatremia could be the expression of iatrogenicfree water loss induction aimed at containing alveolar imbibition for the recovery from $\operatorname{ARDS}(18,19)$. This is supported by two findings: from days 4 to 12 , patients requiring ICU assistance maintained significantly higher sodium levels than the others (data not shown) and, most importantly, 70\% patients with mixed dysnatremia required ICU assistance for ARDS.

The presence of sodium abnormalities at hospital admission for acute medical conditions (whether COVID-19 $(24,34,35)$ or not $(20,21,22,23)$ ) has been associated elsewhere to longer hospitalizations, readmissions after discharge and higher short- and longterm mortality rates, even in case of 'borderline dysnatremia' $\left(130 \leq \mathrm{Na}^{+}<135 \mathrm{mmol} / \mathrm{L}\right.$ for hyponatremia, $145<\mathrm{Na}^{+} \leq 150$ $\mathrm{mmol} / \mathrm{L}$ for hypernatremia) (21) and up to $90 \%$ in case of $\mathrm{Na}^{+}>150 \mathrm{mmol} / \mathrm{L}$ (22). Moreover, the prospective evaluation of 90,889 hospitalized adult patients demonstrated that mixed dysnatremia, hospital-acquired hypernatremia, persistent hypernatremia and 'hyponatremia overcorrected to hypernatremia' were independent indicators of in-hospital mortality (23). In the last case, the lifethreatening occurrence of osmotic demyelination should not be forgotten and has been documented also in a case of overcorrected COVID-19-related SIAD (37).

When sodium levels were longitudinally assessed in a large cohort of COVID-19 inpatients, hyponatremia at admission was associated to a 2.18-fold increased likelihood of needing ventilatory support, but in-hospital mortality was 2.34- and 3.05-fold higher in patients exposed, respectively, to hypernatremia or mixed dysnatremia at any time of the hospital stay (35); moreover, the highest mortality rate occurring in patients experiencing the steepest sodium ascending slope in their first 5 days of hospitalization (36).

Interestingly, we confirmed that excessive in-hospital sodium fluctuations, rather than basal sodium levels are the main danger: almost all outcome measures were influenced by $\Delta \mathrm{Na}^{+}{ }_{\text {min-max }}$ or $\mathrm{Na}^{+}{ }_{\text {max }}$ in the whole cohort, and a longer hospitalization was correlated with a lower $\mathrm{Na}^{+}{ }_{\text {min }}$, a higher $\mathrm{Na}^{+}{ }_{\text {max }}$ and a wider $\Delta \mathrm{Na}^{+}{ }_{\text {min-max }}$ in survived patients. Patients experiencing dysnatremia were estimated to require ICU assistance in mean 20 days earlier than normonatremic ones (Fig. 1). In-hospital death was more likely in elder patients $(\rho=0.260, P=0.005)$, where elevated sodium levels have been extensively observed $(24,32,35)$. Of note, the day-by-day sodium fluctuations experienced by dead patients were absent among those who were discharged, whose sodium trend perfectly traced the whole cohort findings. A similar discrepancy was found when comparing the saw-tooth 21-day sodium pattern of hypernatremic (group C) patients to the harmonious curves of hyponatremic (group A) and normonatremic (group B) ones (Fig. 2). Moreover, the subgroup analysis reflected the results obtained for the whole cohort: dysnatremic patients (group $\mathrm{A}+\mathrm{C}$ ) who had been directly admitted in ICU (notably, 44\% of the study cohort, Supplementary Table 2) had higher sodium levels and a wider sodium variability; moreover, $\mathrm{Na}^{+}{ }_{\text {max }}, \Delta \mathrm{Na}^{+}{ }_{\text {min-max }}$ and exposure to hypernatremia during the hospital course were associated to worse assistance outcomes.

Limitations of this study include the retrospective design and the lack of information on $\mathrm{PaO}_{2} / \mathrm{FiO}_{2}$ ratio or factors affecting sodium balance (hyperglycemia, other patient's comorbidities, administered drugs/infusions, daily water balance), which was due to the current pandemic situation and its adjoining urgent needs. Anyway, we believe that our original, exclusive focus on all possible sodium patterns throughout a 21-day observation period in a relatively large cohort is the main strength of this study: as very recently suggested elsewhere (36), the day-by-day assessment of sodium levels enabled us to highlight excessive longitudinal sodium trajectories, rather than natremia itself, as the best indicator of COVID-19 evolution toward respiratory complications, longer hospitalization and death. Prospective confirmation of these findings is needed, but prompt and careful management of sodium imbalances would certainly bring positive repercussions in reverting the natural history of severe COVID-19 in clinical practice.

\section{Conclusions}

Hospitalized patients with COVID-19 are frequently affected by sodium balance disorders. Besides hyponatremia, which could primarily representa diagnosticratherthan a prognostic biomarker in COVID-19 pneumonia, hypernatremia plays a

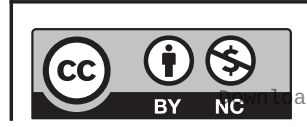

This work is licensed under a Creative Commons Attribution-NonCommercial 4.0 International License. ded from Bioscientifica.com at 04/26/2023 09:04:25AM 
crucial role, particularly when resulting from the correction of the opposite alteration. Patients experiencing mixed dysnatremia have a worse prognosis, mainly in terms of length of their hospitalization and need for ICU assistance/ mechanical ventilation. Further exploration of the interplay between sodium and inflammatory markers (CRP and IL-6 above all) is needed in order to help clinicians in stratifying COVID-19 patients at different risk for disease progression since hospital admission; moreover, the subtle optimization of sodium balance by effectively preventing, through serial measurements, and properly correcting sodium alterations is of paramount importance to improve hospitalized COVID-19 patients' prognosis.

\section{Supplementary materials}

This is linked to the online version of the paper at https://doi.org/10.1530/ EC-21-0411.

\section{Declaration of interest}

The authors declare that there is no conflict of interest that could be perceived as prejudicing the impartiality of the research reported.

\section{Funding}

This work did not receive any specific grant from any funding agency in the public, commercial, or not-for-profit sector.

\section{Ethics approval}

The study was conducted in accordance with the ethical standards for research involving human participants. Protocol approval for the evaluation of epidemiologic and prognostic value of sodium alterations in COVID-19 patients was obtained from the Ethical Committee of the University Hospital of Ancona.

\section{Consent to participate}

Informed consent was obtained from all individual participants included in the study.

\section{Data availability}

The datasets generated and analyzed are available from the corresponding author on reasonable request.

\section{Author contribution statement}

$M M$ and $G A$ designed the study. $M M$ and $F S$ recruited patients. $M M, P$ F, G G, A C and G S collected the data. M M, P F, G S, A T and G A analyzed the data. M M, P F, G S, A T and G A interpreted the data. M M, P F and G A drafted the manuscript. $M M, P F, G S$ and $G$ A created figures. $M M, P F, G$ G, A C, G S, F S, A T and G A critically revised the manuscript for important intellectual content.

\section{Acknowledgements}

The authors wish to thank all health care professionals engaged in Ancona University Hospital 'COV' areas, whose precious contribution made this study possible, helping us doing better and better in fighting this emergency.

\section{References}

1 Sbardella E, Isidori AM, Arnaldi G, Arosio M, Barone C, Benso A, Berardi R, Capasso G, Caprio M, Ceccato F, et al. Approach to hyponatremia according to the clinical setting: consensus statement from the Italian Society of Endocrinology (SIE), Italian Society of Nephrology (SIN), and Italian Association of Medical Oncology (AIOM). Journal of Endocrinological Investigation 201841 3-19. (https:// doi.org/10.1007/s40618-017-0776-x)

2 Spasovski G, Vanholder R, Allolio B, Annane D, Ball S, Bichet D, Decaux G, Fenske W, Hoorn EJ, Ichai C, et al. Clinical practice guideline on diagnosis and treatment of hyponatraemia. European Journal of Endocrinology 2014170 G1-G47. (https://doi.org/10.1530/ EJE-13-1020)

3 Winkler AW \& Crankshaw OF. Chloride depletion in conditions other than Addison's disease. Journal of Clinical Invesigation 193817 1-6. (https://doi.org/10.1172/JCI100920)

4 Viasus D, Marinescu C, Villoslada A, Cordero E, Gálvez-Acebal J, Fariñas MC, Gracia-Ahufinger I, Fernández-Navarro A, Niubó J, Ortega L, et al. Community-acquired pneumonia during the first post-pandemic influenza season: a prospective, multicentre cohort study. Journal of Infection 201367 185-193. (https://doi.org/10.1016/j. jinf.2013.05.006)

5 García-Sanz MT, Martínez-Gestoso S, Calvo-Álvarez U, DovalOubiña L, Camba-Matos S, Rábade-Castedo C, Rodríguez-García C \& González-Barcala FJ. Impact of hyponatremia on COPD exacerbation prognosis. Journal of Clinical Medicine 20209 503. (https://doi. org/10.3390/jcm9020503)

6 Potasso L, Sailer CO, Blum CA, Cesana-Nigro N, Schuetz P, Mueller B $\&$ Christ-Crain M. Mild to moderate hyponatremia at discharge is associated with increased risk of recurrence in patients with community-acquired pneumonia. European Journal of Internal Medicine 202075 44-49. (https://doi.org/10.1016/j.ejim.2019.12.009)

7 Krüger S, Ewig S, Giersdorf S, Harmann O, Frechen D, Rohde G, Suttorp N, Welte T \& CAPNETZ Study Group. Dysnatremia, vasopressin, atrial natriuretic peptide and mortality in patients with community-acquired pneumonia: results from the German competence network CAPNETZ. Respiratory Medicine 2014108 1696-1705. (https://doi.org/10.1016/j.rmed.2014.09.014)

8 Zilberberg MD, Exuzides A, Spalding J, Foreman A, Graves Jones AG, Colby C \& Shorr AF. Hyponatremia and hospital outcomes among patients with pneumonia: a retrospective cohort study. $B M C$ Pulmonary Medicine 20088 16. (https://doi.org/10.1186/14712466-8-16)

9 Kim MA, Park JS, Lee CW \& Choi WI. Pneumonia severity index in viral community acquired pneumonia in adults. PLoS ONE 201914 e0210102. (https://doi.org/10.1371/journal.pone.0210102)

10 Fine MJ, Auble TE, Yealy DM, Hanusa BH, Weissfeld LA, Singer DE, Coley CM, Marrie TJ \& Kapoor WN. A prediction rule to identify low-risk patients with community-acquired pneumonia. New England Journal of Medicine 1997336 243-250. (https://doi.org/10.1056/ NEJM199701233360402)

11 Melmed S. Series introduction. The immuno-neuroendocrine interface. Journal of Clinical Investigation 2001108 1563-1566. (https:// doi.org/10.1172/JCI14604)

12 Hodax JK, Bialo SR \& Yalcindag A. SIADH in systemic JIA resolving after treatment with an IL-6 inhibitor. Pediatrics 2018141 e20164174. (https://doi.org/10.1542/peds.2016-4174) 
13 Wang D, Hu B, Hu C, Zhu F, Liu X, Zhang J, Wang B, Xiang H, Cheng Z, Xiong Y, et al. Clinical characteristics of 138 hospitalized patients with 2019 novel coronavirus-infected pneumonia in Wuhan, China. JAMA 2020323 1061-1069. (https://doi.org/10.1001/ jama.2020.1585)

14 Huang C, Wang Y, Li X, Ren L, Zhao J, Hu Y, Zhang L, Fan G, Xu J, $\mathrm{Gu}$ X, et al. Clinical features of patients infected with 2019 novel coronavirus in Wuhan, China. Lancet 2020395 497-506. (https://doi org/10.1016/S0140-6736(20)30183-5)

$15 \mathrm{Wu}$ Z \& McGoogan JM. Characteristics of and important lessons from the coronavirus disease 2019 (COVID-19) outbreak in China: summary of a report of 72314 cases from the Chinese Center for Disease Control and Prevention. JAMA 2020323 1239-1242. (https://doi.org/10.1001/ jama.2020.2648)

16 Onder G, Rezza G \& Brusaferro S. Case-fatality rate and characteristics of patients dying in relation to COVID-19 in Italy. JAMA 2020323 1775-1776. (https://doi.org/10.1001/jama.2020.4683)

17 Baud D, Qi X, Nielsen-Saines K, Musso D, Pomar L \& Favre G. Real estimates of mortality following COVID-19 infection. Lancet: Infectious Diseases 202020 773. (https://doi.org/10.1016/S14733099(20)30195-X)

18 Lindner G \& Funk GC. Hypernatremia in critically ill patients. Journal of Critical Care 201328 216.e11-216.e20. (https://doi.org/10.1016/j. jcrc.2012.05.001)

19 Lindner G, Kneidinger N, Holzinger U, Druml W \& Schwarz C. Tonicity balance in patients with hypernatremia acquired in the intensive care unit. American Journal of Kidney Diseases 200954 674-679. (https://doi.org/10.1053/j.ajkd.2009.04.015)

20 Kutz A, Ebrahimi F, Aghlmandi S, Wagner U, Bromley M, Illigens B, Siepmann T, Schuetz P, Mueller B \& Christ-Crain M. Risk of adverse clinical outcomes in hyponatremic adult patients hospitalized for acute medical conditions: a population-based cohort study. Journal of Clinical Endocrinology and Metabolism 2020105 3428-3436. (https:// doi.org/10.1210/clinem/dgaa547)

21 Girardeau Y, Jannot AS, Chatellier G \& Saint-Jean O. Association between borderline dysnatremia and mortality insight into a new data mining approach. BMC Medical Informatics and Decision Making 2017 17 152. (https://doi.org/10.1186/s12911-017-0549-7)

22 Akirov A, Diker-Cohen T, Steinmetz T, Amitai O \& Shimon I. Sodium levels on admission are associated with mortality risk in hospitalized patients. European Journal of Internal Medicine 201746 25-29. (https:// doi.org/10.1016/j.ejim.2017.07.017)

23 Hu J, Wang Y, Geng X, Chen R, Zhang P, Lin J, Teng J, Zhang X \& Ding X. Dysnatremia is an independent indicator of mortality in hospitalized patients. Medical Science Monitor 201723 2408-2425. (https://doi.org/10.12659/msm.902032)

$24 \mathrm{Hu}$ W, Lv X, Li C, Xu Y, Qi Y, Zhang Z, Li M, Cai F, Liu D, Yue J, et al. Disorders of sodium balance and its clinical implications in COVID-19 patients: a multicenter retrospective study. Internal and Emergency Medicine 202116 853-862. (https://doi.org/10.1007/ s11739-020-02515-9)

25 Wu Y, Hou B, Liu J, Chen Y \& Zhong P. Risk factors associated with long-term hospitalization in patients with COVID-19: a singlecentered, retrospective study. Frontiers in Medicine 20207 315. (https:// doi.org/10.3389/fmed.2020.00315)

26 Choi KW, Chau TN, Tsang O, Tso E, Chiu MC, Tong WL, Lee PO, $\mathrm{Ng}$ TK, Ng WF, Lee KC, et al. Outcomes and prognostic factors in 267 patients with severe acute respiratory syndrome in Hong Kong. Annals of Internal Medicine 2003139 715-723. (https://doi.org/10.7326/00034819-139-9-200311040-00005)

27 Akbar MR, Pranata R, Wibowo A, Irvan STA \& Martha JW. The prognostic value of hyponatremia for predicting poor outcome in patients with COVID-19: a systematic review and meta-analysis. Frontiers of Medicine 20218 666949. (https://doi.org/10.3389/ fmed.2021.666949)

28 Berni A, Malandrino D, Parenti G, Maggi M, Poggesi L \& Peri A. Hyponatremia, IL-6, and SARS-CoV-2 (COVID-19) infection: may all fit together? Journal of Endocrinological Investigation 202043 1137-1139. (https://doi.org/10.1007/s40618-020-01301-w)

29 Zhou F, Yu T, Du R, Fan G, Liu Y, Liu Z, Xiang J, Wang Y, Song B, $\mathrm{Gu} X$, et al. Clinical course and risk factors for mortality of adult inpatients with COVID-19 in Wuhan, China: a retrospective cohort study. Lancet 2020395 1054-1062. (https://doi.org/10.1016/S01406736(20)30566-3)

30 De Carvalho H, Letellier T, Karakachoff M, Desvaux G, Caillon H, Papuchon E, Bentoumi-Loaec M, Benaouicha N, Canet E, Chapelet G, et al. Hyponatremia is associated with poor outcome in COVID-19. Journal of Nephrology 202134 991-998. (https://doi.org/10.1007/ s40620-021-01036-8)

31 Tezcan ME, Dogan Gokce G, Sen N, Zorlutuna Kaymak N \& Ozer RS Baseline electrolyte abnormalities would be related to poor prognosis in hospitalized coronavirus disease 2019 patients. New Microbes and New Infections 202037 100753. (https://doi.org/10.1016/j. nmni.2020.100753)

32 Frontera JA, Valdes E, Huang J, Lewis A, Lord AS, Zhou T, Kahn DE, Melmed K, Czeisler BM, Yaghi S, et al. Prevalence and impact of hyponatremia in patients with coronavirus disease 2019 in New York City. Critical Care Medicine 202048 e1211-e1217. (https://doi. org/10.1097/CCM.0000000000004605)

33 Berni A, Malandrino D, Corona G, Maggi M, Parenti G, Fibbi B, Poggesi L, Bartoloni A, Lavorini F, Fanelli A, et al. Serum sodium alterations in SARS CoV-2 (COVID-19) infection: impact on patient outcome. European Journal of Endocrinology 2021185 137-144. (https:// doi.org/10.1530/EJE-20-1447)

34 Ghahramani S, Tabrizi R, Lankarani KB, Kashani SMA, Rezaei S, Zeidi N, Akbari M, Heydari ST, Akbari H, Nowrouzi-Sohrabi P, et al. Laboratory features of severe vs non-severe COVID-19 patients in Asian populations: a systematic review and meta-analysis. European Journal of Medical Research 202025 30. (https://doi.org/10.1186/ s40001-020-00432-3)

35 Ruiz-Sánchez JG, Núñez-Gil IJ, Cuesta M, Rubio MA, Maroun-Eid C, Arroyo-Espliguero R, Romero R, Becerra-Muñoz VM, Uribarri A, Feltes $\mathrm{G}$, et al. Prognostic impact of hyponatremia and hypernatremia in COVID-19 pneumonia. A HOPE-COVID-19 (health outcome predictive evaluation for COVID-19) registry analysis. Frontiers in Endocrinology 202011 599255. (https://doi.org/10.3389/ fendo.2020.599255)

36 Tzoulis P, Waung JA, Bagkeris E, Hussein Z, Biddanda A, Cousins J, Dewsnip A, Falayi K, McCaughran W, Mullins C, et al. Dysnatremia is a predictor for morbidity and mortality in hospitalized patients with COVID-19. Journal of Clinical Endocrinology and Metabolism 2021106 1637-1648. (https://doi.org/10.1210/clinem/dgab107)

37 Saleh AO, Al-Shokri SD, Ahmed AOE, Musa AE \& Mohamed MFH. Urinary retention and severe hyponatremia: an unusual presentation of COVID-19. European Journal of Case Reports in Internal Medicine 2020 7 001905. (https://doi.org/10.12890/2020_001905)

Received in final form 13 September 2021

Accepted 17 September 2021

Accepted Manuscript published online 17 September 2021 https://ec.bioscientifica.com https://doi.org/10.1530/EC-21-0411 (c) 2021 The authors Published by Bioscientifica Ltd

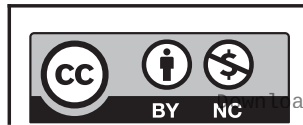

This work is licensed under a Creative Commons Attribution-NonCommercial 4.0 International License. ded from Bioscientifica com at 04/26/2023 09:04:25AM 